\title{
E. JÜNGER: ESCRITURA DE GUERRA Y PENSAMIENTO ANTROPOLÓGICO
}

\author{
E. JÜNGER: WRITING OF WAR AND ANTHROPOLOGICAL THOUGHT
}

\author{
Luisa Paz Rodríguez Suárez \\ Universidad de Zaragoza (España)
}

Recibido: 20-05-2012

Aceptado: 26-06-2012

Resumen: Este trabajo expone algunos de los elementos centrales que configuran el pensamiento antropológico que Jünger elabora en sus diarios de guerra. Un género de escritura, característico de nuestra época, que surge no tanto de un propósito literario como de un intento por captar y expresar lo real. Por este motivo su escritura de guerra trasciende lo que sería una expresión de lo personal para convertirse en un instrumento de reflexión de un tiempo que es también el nuestro. En ella se produce una particular meditación filosófica sobre el ser humano y su condición en el mundo contemporáneo, que persigue, en última instancia, revelar el orden invisible del mundo, la lógica de los acontecimientos que conforman nuestra realidad.

Palabras-clave: Ernst Jünger, diarios de guerra, antropología filosófica, trabajo, técnica.

\begin{abstract}
This paper displays some of the main elements that form the anthropological thought that Jünger develops with his war diaries. An specific kind of writing, characteristic of our times, that comes up not precisely from a literary aim but from an attempt to catch and express the real. For that reason his writing of war transcends what would be an expression of the personal self to become a reflection tool for a time that is also our own time. A particular philosophical meditation is made in it about the human being and his condition in the contemporary world, looking ultimately for revealing the invisible order of the world, the logic of events that form our reality.

Key-words: Ernst Jünger, war diaries, philosophical anthropology, work, technique.
\end{abstract}


“Con talento escriben pocos. ¿Pero hay tantos que lean con talento?”' Esta es la pregunta que se plantea Jünger, haciendo suyas las palabras de otro escritor. Y me parece que es también la que podríamos hacer nosotros al acercarnos a su obra. Una obra difícil que exige mucho a sus lectores. Entre otros motivos, porque su escritura promueve una modificación de la mirada que resulta indispensable para alcanzar lo que persigue, que no es otra cosa que permitir ver al ser humano. Y ello en el doble sentido de la expresión: hacer visible a la persona singular y, a la vez, que ésta sea capaz de alcanzar una representación de la realidad lo más amplia posible. En 1932 escribe a propósito de esto algo que quizá no sólo siga siendo válido, sino que en el siglo actual cobre aún más vigencia si cabe; un tiempo en el que el carácter abstracto de las cosas y los seres humanos nos ha alejado de lo real, incluso de nosotros mismos: "Para llegar a ver al ser humano se necesita ciertamente un esfuerzo especial -y esto no deja de ser raro en una edad en la que el ser humano aparece en masse"2.

Algunos de los aspectos en los que radica la dificultad de la escritura de Ernst Jünger tiene que ver en con la propia concepción que de la misma tiene el autor alemán. Me gustaría reflexionar a continuación sobre ella, una "escritura de guerra" en la que se produce una meditación sobre el ser humano que pretende ejercerse sin ningún tipo de atadura política, ideológica o moral. Como apunta en uno de sus diarios, escrito durante la Segunda Guerra Mundial: "Los seres humanos son textos jeroglíficos, pero muchos encuentran su Champollion. Se hacen legibles, se vuelven interesantes, cuando se afina la clave con amore"3.

A pesar de ser un gran naturalista, Jünger no es un científico; y, aunque sea interlocutor privilegiado de filósofos, tampoco es un filósofo propiamente dicho. Y menos si por tal se entiende la comprensión que la filosofía tenía de sí misma en las dos primeras décadas del siglo XX, que es la época en la que transcurre su juventud. Ya desde entonces prefirió el arte a la ciencia o la filosofía, porque tiene el convencimiento de que "en la obra de arte hay una gigantesca fuerza de orientación"4.

Jünger es, pues, un escritor. Y cuando emplea esta palabra para referirse a sí mismo, la utiliza haciéndola sinónima de poeta, de artista, por eso suele hablar más bien de escritura. Él dice que, aunque "la filosofía siempre le ha atraído e interesado, su elección de vida" ha sido la escritura; porque, en su opinión, "el verdadero escritor [...] es como una luz que, invisible en sí misma, calienta y hace visible el mundo" . En este sentido no cabe entender su obra

[1] E. Jünger, El autor y la escritura, Barcelona, Gedisa, 2003, p. 92.

[2] E. Jünger, El Trabajador. Dominio y figura, Barcelona, Tusquets, 1990, p. 99.

[3] E. Jünger, Radiaciones II, Barcelona, Tusquets, 2005, p. 596.

[4] E. Jünger, Radiaciones I, Barcelona, Tusquets, 2005, p. 13.

[5] A. Gnoli y F. Volpi, Los titanes venideros, Barcelona, Península, 2007, pp. 121 y 58.

THÉMATA. Revista de Filosofía, Nº48 julio-diciembre (2013) pp.: 191-199 doi: 10.12795/themata.2013.i48.17 
como una expresión de sus vivencias sin más, sino que se trataría más bien de una lírica del pensamiento con la que pretende expresar lo real. Jünger sería lo que en alemán se conoce como un Dichterphilosoph, un poeta-filósofo, una expresión con la que se quiere manifestar el carácter productivo, poético en sentido estricto, de todo pensamiento genuino.

Su obra, por tanto, no se deja encuadrar fácilmente ni como filosofía ni como literatura, sino que desafía precisamente ambos géneros para llevarlos más allá de sí. Como hemos dicho, en ella se abre paso un pensamiento sobre el ser humano de nuestro tiempo: un pensamiento antropológico que viene a confirmar ese espacio de diálogo entre filosofía y literatura, típico del quehacer intelectual contemporáneo. Jünger es un escritor, un artista situado en la estela de Nietzsche -por otra parte, tan admirado por él- al que incluso algunos han llegado a ver como el Nietzsche del siglo XXI. Hay quienes -como Peter Koslowski- han calificado su obra como "filosofía poética [dichterische Philosophie]", dado que "rebasa los límites de la poesía, el mito, la historia y la filosofía" ${ }^{6}$, formando una original síntesis entre ellas. En este contexto debemos situar la afirmación del escritor: "El mito emerge en todos los tiempos" ${ }^{7}$. Y me parece que algo que es consustancial al mito -y que también se aprecia en su escritura- es que no busca hablar sobre la verdad, sino producirla, hacerla real; intentando revelar la estructura metafísica del mundo, su orden invisible. En este sentido podría decirse que la suya es una escritura que quiere dar voz al ser. De ahí que él mismo defina la tarea del autor diciendo que consiste en "hacer surgir del mundo histórico y natural un tercer mundo, que, si bien está contenido en ambos, permanecería sin él oculto hasta el Juicio Final"8.

Su obra se compone de diarios, narrativa y ensayos -como él dice- "acerca de nuestra época" y atraviesa prácticamente todo el siglo XX; un tiempo en el que, tras las dos guerras mundiales, se produce una quiebra irreversible de la imagen moderna del ser humano y con ella de los fundamentos que sustentaban su autocomprensión. En este contexto surgen los diarios -entre otros y de manera muy destacada los de Jünger-que constituyen un género particular característico del mundo contemporáneo. Para el escritor, su importancia como elemento de reflexión radica en que "el diario no es tan sólo una experiencia personal, sino que es al mismo tiempo un género de escritura", es más, una "escritura privilegiada". Y lo es, entre otras razones, porque se trata de una escritura que no ha surgido tanto de un propósito literario -como señala en

[6] P. Koslowski, Der Mythos der Moderne. Die dichterische Philosophie Ernst Jüngers, München, W. Fink Verlag, 1991, pp. 15-16.

[7] El Trabajador, pp. 93-94.

[8] El autor y la escritura, p. 49.

[9] Los titanes venideros, pp. 118-119.

THÉMATA. Revista de Filosofía, №48 julio-diciembre (2013) pp.: 191-199 doi: 10.12795/themata.2013.i48.17 
La emboscadura (1951) ${ }^{10}$ - como de la necesidad de ese hacer visible el orden invisible del mundo en un siglo atravesado por la devastación de la guerra. Una escritura de guerra nacida en los remolinos de la catástrofe y producida en un tiempo particularmente oscuro para la humanidad. Un tiempo en el que -como él afirma11_ "lo pretérito no es ya real y lo venidero no es aún visible" y en el que -como ahora ya podemos ver- nuestro presente actual comenzaba entonces a dibujarse.

Jünger escribió diarios durante la Primera Guerra Mundial, de 1914 a 1918; en concreto catorce cuadernos, sobre la base de los cuales publicó en 1920 su primera obra Tempestades de acero. Y también escribió otros seis diarios de guerra durante la segunda, de 1939 a 1945. En el primero de ellos, titulado Jardines y carreteras, subraya cómo "el carácter de diario se convierte en un carácter específico de la literatura" ${ }^{12}$. Una de las razones fundamentales reside en que este género de escritura constituye "un instrumento característico de autorreflexión y comprensión del tiempo" ${ }^{13}$. No es otra cosa, en definitiva, lo que Jünger perseguirá durante toda su vida: comprender la sustancia de su época, que es también la nuestra. Por eso con su obra se ha convertido en testigo de nuestro tiempo, de todo un siglo; un referente necesario para intentar entender uno de los períodos más convulsos e impredecibles, sobre todo si nos situamos en la perspectiva de principio del siglo XX. Testimonios como el suyo van mucho más allá de una expresión de lo personal, pues lo que buscan es contribuir a expresar la lógica de la barbarie. Muy pocos, como Nietzsche, supieron anticipar, en medio de la seguridad y el optimismo característico de finales del XIX y principios del XX, las grandes catástrofes que aguardaban al ser humano y que efectivamente ocurrieron apenas comenzó el siglo.

Jünger ha titulado sus diarios de la Segunda Guerra Mundial con la palabra Strahlungen, Radiaciones. En la entrevista que concedió en 1995 a Franco Volpi le explicó que ésta "es una palabra casi metafísica, como emanación" y que "indica un modo de transmitirse de la energía, tanto en sentido material como en sentido espiritual" ${ }^{14}$. Radiaciones es el título de este sexteto de diarios que, tomados en conjunto, dan lo que su autor llama "la imagen de la catástrofe". Como escribe al respecto: "Completamente oscuras son las grandes zonas del terror que a partir del final de la Primera Guerra Mundial van penetrando en nuestro tiempo y propagándose de manera funesta". Señala, entre otros, a Nietzsche, Melville, Poe, Hölderlin, Dostoievski, Conrad, Kierkegaard,

[10] E. Jünger, La emboscadura, Barcelona, Tusquets, 2002, p. 133.

[11] El Trabajador, pp. 93 y 96.

[12] Radiaciones I, p. 11.

[13] H. Wegener (ed.), Ernst Jünger y sus pronósticos del tercer Milenio, Madrid, Editorial Complutense, 2006, p.16.

[14] Los titanes venideros, p. 59.

THÉMATA. Revista de Filosofía, Nº48 julio-diciembre (2013) pp.: 191-199 doi: 10.12795/themata.2013.i48.17 
como "augures de las profundidades del Maelstrom a que hemos descendido", como ejemplo de literatura de la catástrofe, la que nace de sus remolinos: "La catástrofe fue prevista en todos sus detalles. Pero a menudo los textos eran jeroglíficos -hay así obras para las cuales no hemos madurado como lectores hasta hoy" ${ }^{15}$.

Jardines y carreteras narra el avance del ejército alemán a través del territorio francés y está escrito desde una total oposición al nazismo. Este diario supone un cambio de perspectiva radical en la visión de la guerra respecto a los que escribió en la Primera. En Tempestades de acero el soldado era visto como un hombre de acción y la guerra aparecía como una gran aventura. En la primera página podemos leer: "Crecidos en una era de seguridad, sentíamos todos un anhelo de cosas insólitas, de peligro grande. Y entonces la guerra nos había arrebatado como una borrachera [...]. La guerra nos parecía un lance viril" ${ }^{16}$. Muy distinta será la impresión que tendrá de la Segunda; en Jardines y carreteras prevalece la perspectiva del individuo expuesto al sufrimiento, al dolor y a la muerte ${ }^{17}$. Este diario es el primero de los escritos durante la Segunda Guerra Mundial, fue comenzado el 3 de abril de 1939 y apareció en ese mismo año. Por estas mismas fechas estaba ultimando su relato más famoso, Sobre los acantilados de mármol; en él dice a través de sus personajes: "el error sólo se convierte en falta, cuando se persiste en él", ya que "hay experiencias que nos obligan a hacer una profunda revisión de conceptos" ${ }^{18}$.

Para él, escribir es una de las tareas "más excelsas de este mundo", pero "no por ello deja de entrañar un riesgo muy alto" ${ }^{19}$. En su empresa el escritor no sólo arriesga el lenguaje, sino que haciéndolo, se arriesga con él, debido a la naturaleza histórica que lo constituye. Así lo constata cuando afirma: "en el lenguaje siempre hay historia" ${ }^{20}$. Por ello no es de extrañar que, ante el desmoronamiento espiritual, cifre como deber del escritor "captar la decadencia en su dimensión global, en su significado trágico [...]", dado que su misión no es otra que una captación de lo invisible. Una tarea que él sitúa próxima a la "de los grandes profetas" o a aquellos que, como Heráclito, buscan la ley de los acontecimientos ${ }^{21}$. Su intención no es, como ya se ha dicho, expresarse a sí mismo, sino que la tarea de su escritura consiste en "la captación espiritual de la catástrofe". Si el escritor cumple con este deber, Jünger piensa que entonces no

[15] Radiaciones I, pp. 11-13.

[16] Tempestades de acero, Barcelona, Tusquets, 2005, p. 5.

[17] Radiaciones I, III-IV.

[18] Sobre los acantilados de mármol, Barcelona, Destino, 2004, p. 28.

[19] Radiaciones I, p. 14.

[20] El autor y la escritura, p.65.

[21] Los titanes venideros, p. 59.

THÉMATA. Revista de Filosofía, No 48 julio-diciembre (2013) pp.: 191-199 doi: 10.12795/themata.2013.i48.17 
hay que echarle la culpa al sismógrafo -como cree que le sucedió injustamente a Nietzsche- porque lo único que hace es eso, captar y expresar la catástrofe:

La captación espiritual de la catástrofe es más temible que los horrores reales del fuego. Esa captación es un riesgo que sólo pueden correr los espíritus más osados, los capaces de soportar grandes cargas, de hacer frente a las dimensiones de los acontecimientos, bien que no a su peso. Quedar despedazado de ese modo fue el destino de Nietzsche, lapidar al cual es hoy de buen tono. Después de un terremoto la gente golpea a los sismógrafos. Pero si no queremos contarnos en el número de los primitivos, no podemos hacer expiar a los barómetros los tifones ${ }^{22}$.

Me gustaría detenerme en otro aspecto de su escritura relacionado con esta expresión de la lógica de la barbarie. Y es que tal expresión tiene como finalidad, no sólo hacerla visible para sus contemporáneos, sino, ante todo, para sí mismo. En este sentido cabe entender, pues, la intención autodidáctica que confiere a su escritura, ejercida siempre como un acto de independencia. La misión de sus escritos, según sus propias palabras, "no es política, sino pedagógica, autodidáctica en un sentido superior: el autor permite al lector que comparta su evolución", pues la finalidad a la que deben servir -como dice- es a su "propia formación". Y es que, para él, en nuestro mundo también forma parte del lujo "el modo propio de ser, el ethos", lo que le lleva a concluir que "la lucha por un modo propio de ser, la voluntad de salvaguardar[lo] [...] es uno de los trágicos asuntos de nuestro tiempo" ${ }^{23}$, pues tiene que hacer frentre a la creciente abstracción a la que va siendo sometida la persona concreta.

Como ya hemos dicho, en Jardines y carreteras ofrece una visión de la guerra desde una perspectiva nueva, la del sufrimiento. El soldado ya no es el hombre de acción de su otro relato bélico Tempestades de acero. Ahora el soldado "es el individuo sometido a la disciplina, amenazado por la muerte, expuesto al dolor". Y descubre que la guerra tiene un carácter eminentemente técnico, son batallas de material, mecánicas, hasta el punto de que "la máquina otorga una impronta matemática a los encuentros bélicos" ${ }^{24}$. Apenas cinco años antes, en 1934, Jünger escribe Sobre el dolor, un ensayo en el que afirma que "el dolor es una de esas llaves con que abrimos las puertas no sólo de lo más íntimo, sino a la vez del mundo". La razón de ello, en su opinión, estriba en que el dolor es uno de los criterios "en los cuales se hace patente el significado del ser humano"; es en él "donde se esconde la auténtica piedra de toque de la realidad" ${ }^{25}$. El escritor constata cómo en cada época se da una valoración distinta del dolor y lo relaciona con la objetización de nuestra imagen del mundo. Una valoración que atraviesa y conecta los fenómenos del trabajo, la técnica y la guerra. Su

[22] Radiaciones I, p. 11.

[23] Ib., pp. 15-16 y 20.

[24] Tempestades de acero, pp. III-IV y 60.

[25] Sobre el dolor, Barcelona, Tusquets, 2003, pp. 13 y 82.

THÉMATA. Revista de Filosofía, Nº48 julio-diciembre (2013) pp.: 191-199 doi: 10.12795/themata.2013.i48.17 
conclusión será que la guerra es un escenario privilegiado donde puede verse la emergente esencia de nuestra época: la técnica. La técnica y la modificación antropológica respecto a nuestra relación con el dolor que requiere. Una modificación que conlleva, a su vez, la transformación de la persona singular en objeto y, a la postre, en masa.

Este ensayo fue escrito, como digo, en 1934 y, visto desde la perspectiva del presente, se convierte en un documento de génesis del mismo. En él Jünger sostiene la tesis de que "nuestra relación con el dolor se ha modificado". Nuestra valoración del dolor ha cambiado respecto del mundo de la seguridad del siglo XIX. En su mundo -que es también el nuestro- el dolor aparece como algo que hay que evitar. Por este motivo, para distanciarse de él y poder excluirlo de la vida -dice- "el ser humano es capaz de tratar el cuerpo -es decir, el espacio mediante el cual participa en el dolor [y lo interpreta]- como un objeto". Esa objetización, esa "conformación del carácter de objeto" de la persona singular es, para Jünger, "una característica segura de todos los espacios donde el dolor representa una experiencia directa". Y también lo considera, entre otros aspectos, "un síntoma del incremento de los equipamientos bélicos". "El uniforme -sostiene- envuelve un carácter de equipamiento bélico, una exigencia de poseer una coraza especial contra la agresión del dolor" ${ }^{26}$. Una coraza que lo aleja y que hace posible elaborar una distancia respecto de él.

De este modo, la distancia se convierte en un presupuesto del dominio: "El general en jefe mira las cosas sin que las irradiaciones del dolor y la pasión lo afecten". En las batallas el ser humano ni siquiera ve la muerte, "porque está ocupado en servir a instrumentos". Y advierte "de que los ejércitos vayan a adquirir, cada vez más, un carácter de objeto, y ello tanto en lo que concierne a las armas como en lo que se refiere a los combatientes" ${ }^{27}$. Para que esto sea así ha de darse, en su opinión, una condición indispensable: la "transformación de la masa por la cual pasa de ser una magnitud moral a ser un mero objeto". Así, en las batallas navales no se ve al combatiente, que es invisible, ni siquiera una masa de combatientes; "lo que vemos es la flota o el buque". Según su diagnóstico, lo que hace posible este proceso es un mecanismo propio de la sociedad de masas: la transformación de las realidades en abstracciones, en conceptos generales. Un ejemplo muy claro de ello sería la transformación de los bienes en dinero ${ }^{28}$.

Para Jünger, donde "se refleja con máxima claridad la creciente objetización de nuestra vida" es en el orden técnico. La "conversión en objeto" de la vida se entiende en nuestra época como una estrategia para conjurar el dolor e impermeabilizarse contra él. De ahí que concluya que el ser humano

[26] Ib., pp. 34-35, 57 y 46.

[27] Ib., pp. 60, 64 y 66.

[28] Ib., pp. 63 y 27.

THÉMATA. Revista de Filosofía, Nº48 julio-diciembre (2013) pp.: 191-199 doi: 10.12795/themata.2013.i48.17 
está siendo sometido de manera imperceptible a lo que denomina una "revolución objetiva". Una revolución que, en definitiva, expresa la estrecha conexión entre técnica, trabajo y guerra, y que resume diciendo: "La técnica es nuestro uniforme" ${ }^{29}$, "el uniforme del trabajador". La técnica es concebida como el instrumento, la proyección, de un nuevo modo de vida que se abre paso. Este modo de vida es el trabajo y domina todas las esferas de la actividad humana. De manera que cualquier situación, incluído el descanso o el ocio, es concebida como trabajo: "El carácter total de trabajo es el modo en que la figura del trabajador está comenzando a penetrar en el mundo" ${ }^{30}$. Por eso afirma que la técnica es "la lengua mundial. Es subliminar y universal como la música" ${ }^{31}$. En última instancia, es este carácter total de trabajo el que iguala al soldado en el tipo del trabajador, ya que la lucha también aparece como trabajo ${ }^{32}$.

El trabajador es, pues, una nueva figura, un nuevo tipo humano, al que el trabajo se le presenta, en definitiva, como un modo nuevo de vivir, otro modo de vida. La transformación de las realidades en conceptos generales es el procedimiento que sostiene la transformación de la persona singular en tipo. En su ensayo de 1932, El Trabajador, expone esa modificación del individuo mediante la cual se transforma en el tipo del trabajador. Éste tiene un rostro nuevo que es el de nadie: "un rostro carente de alma, trabajado como en metal [...]. Es uno de los rostros en que se expresa el tipo" ${ }^{33}$. Y algo que advierte ya entonces es que hasta el deporte se convierte en trabajo, en una profesión. Augura, en consecuencia, que la educación consistirá en el cultivo de ese tipo y vislumbra la era que se abre como una época del mundo que se caracteriza por la identidad de trabajo y ser, por medio de la cual lo que se pretende es conquistar una nueva seguridad ${ }^{34}$.

Por todo ello, para Jünger "el mundo de la persona singular" ha pasado, "está situado a nuestras espaldas"; es un mundo cuyas valoraciones han sido derrotadas. Pero, tras esta constatación no se esconde una resignación pesismista, pues el escritor está convencido de que la persona singular siempre "es superior a toda masa"; razón por la cual cree que ninguna persona singular "puede estar contenta bajo el dominio de los conceptos generales". La masa es un concepto general y por eso pertenece al mundo de dichos conceptos. Y ese carácter abstracto es un ingrediente fundamental de su insensibilidad: "La masa mata de forma mecánica, despedaza y pisotea" ${ }^{35}$. Asimismo, la técnica

[29] Ib., pp. 59, 58 y 68.

[30] El Trabajador, pp. 343 y 102.

[31] El autor y la escritura, p. 194.

[32] Sobre el dolor, p. 65.

[33] Ib., 40 y 78.

[34] El Trabajador, pp. 89-90.

[35] Sobre el dolor, pp. 36, 39, 31, 49 y 50.

THÉMATA. Revista de Filosofía, Nº48 julio-diciembre (2013) pp.: 191-199 doi: 10.12795/themata.2013.i48.17 
de tratar a las masas tiene ver con el mundo de los conceptos generales. "Un estado total -afirma- presupone la existencia de al menos un único hombre total" y, por consiguiente, produce "una burocracia total". En el mundo técnico el ser humano se convierte en uno de los componentes de ese mundo, uno más entre otros. Su ser queda reducido a mero objeto y el cuerpo aparece como un instrumento más. Por eso "ya no estamos en nuestro cuerpo, a la manera antigua, como en nuestra casa", sino que ha adquirido el carácter de cosa ${ }^{36}$, expulsándonos de nosotros mismos.

Lo que Jünger vislumbra ya entonces es que ese tipo está formándose progresivamente y que irá avanzando hasta nuestros días. Uno de los atributos que lo caracterizan es el de poseer lo que él llama "una segunda consciencia", que no es otra cosa que la capacidad de verse a si mismo como un objeto. La modificación de la conciencia decanta un nuevo tipo, una nueva figura humana. Esta segunda consciencia "se dirige a un hombre situado fuera de la zona del dolor": "La cuantía del dolor susceptible de ser soportado crece a medida que progresa la objetización. Casi parece que el ser humano posee un afán de crear un espacio en el que resulte posible considerar el dolor como una ilusión”. La segunda consciencia justifica ese proceso de objetización de la vida y genera, en última instancia, otro orden simbólico: "En el mundo del trabajador el decurso técnico exacto, que es en igual medida amoral y no caballeresco, reemplaza al rito" ${ }^{37}$.

Así pues, el ser humano resiste el dolor en la medida en que "es capaz de extraerse a sí mismo fuera de sí mismo. Ese extraer fuera de sí la vida, ese cosificarla y objetizarla, va aumentando sin interrupción”. Para Jünger esta es una característica esencial de nuestro mundo, una edad instrumental en la que "preponderan las valoraciones técnicas" y bajo cuya orientación al ser humano se le hacen las mismas exigencias que a una máquina. Una era en la que, como el escritor asegura, "la técnica y el ethos se han vuelto sinónimos" de una manera asombrosa ${ }^{38}$.

[36] Ib., pp. 54, 37-38 y 77-80.

[37] Ib., pp. 74 y 76.

[38] Ib., pp. 83-84.

THÉMATA. Revista de Filosofía, №48 julio-diciembre (2013) pp.: 191-199 doi: 10.12795/themata.2013.i48.17 